Letter to the Editor

\title{
Adjuvant collagen crosslinking for treatment of epithelial ingrowth after small-incision lenticule extraction
}

\author{
Tommy CY Chan FRCS, ${ }^{1}$ George PM Cheng FRCS, ${ }^{2}$ Vishal Jhanji MD ${ }^{3}$ and Yan Wang \\ $\mathrm{MD}^{4}$ \\ ${ }^{1}$ Department of Ophthalmology and Visual Sciences, The Chinese University of Hong \\ Kong, Hong Kong \\ ${ }^{2}$ Hong Kong Laser Eye Centre, Hong Kong \\ ${ }^{3}$ UPMC Eye Center, University of Pittsburgh School of Medicine, Pittsburgh, PA, USA \\ ${ }^{4}$ Tianjin Eye Hospital, Tianjin Eye Institute, Tianjin Key Laboratory of Ophthalmology \\ and Visual Science, Clinical College of Ophthalmology, Tianjin Medical University, \\ Tianjin, China
}

Correspondence: Tommy CY Chan, Department of Ophthalmology and Visual Sciences, The Chinese University of Hong Kong, 147K Argyle Street, Kowloon, Hong Kong

Email: tommychan.me@gmail.com

Received 15 October 2017; accepted 19 October 2017

Conflict of interest: None

Funding sources: None

This is the author manuscript accepted for publication and has undergone full peer review but has not been through the copyediting, typesetting, pagination and proofreading process, which may lead to differences between this version and the Version of Record. Please cite this article as doi: 10.1111/ceo.13094

This article is protected by copyright. All rights reserved. 
Small-incision lenticule extraction (SMILE) is a corneal refractive surgery that utilizes femtosecond laser to create an intrastromal lenticule, which is removed through a small incision. Epithelial ingrowth within the corneal cap-stromal interface has been reported in $0.5 \%$ of eyes. ${ }^{1}$ We report a case of epithelial ingrowth after SMILE, which was managed with collagen crosslinking (CXL) following intrastromal debridement.

A 30-year-old lady reported progressive decrease in vision in her right eye for 3 months after bilateral SMILE surgery. At presentation, the uncorrected distance visual acuity was 20/40 in her right eye and 20/20 in her left eye with manifest refractions of -1.75 cylinder and Plano, respectively. Slit-lamp examination of the right eye showed epithelial ingrowth through the SMILE incision into the cap-stromal interface (Figure $1 \mathrm{~A}$ ). The left eye examination was unremarkable. Corneal topography revealed a focal increase in keratometry and pachymetry overlying the area of epithelial ingrowth (Figure 1B). Anterior segment optical coherence tomography confirmed the presence of epithelial ingrowth within the stromal interface (Figure 1C).

The stromal interface was opened through the SMILE incision. Evidence of previous tear at incision was noticed intraoperatively. We dissected through the interface starting at region far away from the ingrowth. The epithelial ingrowth was removed using the blunt end of a Sinskey hook with a peeling and stripping technique on both surfaces within the stromal pocket. This was followed by thorough irrigation of the stromal pocket with balanced salt solution. The tip of the cannula was placed distal to the ingrowth so that hydraulic pressure could help flush out any residual debris and epithelial cells. Subsequently, isotonic $0.22 \%$ riboflavin in saline (VibeX Xtra: Avedro, Waltham MA, USA) was injected into the stromal interface for 60 seconds. After residual riboflavin was irrigated thoroughly, the edge of incision was dried 
using cellulose sponges. An ultraviolet-A lamp (CCL-Vario, Peschke Trade $\mathrm{GmbH}$, Hünenberg, Switzerland) using $18-\mathrm{mW} / \mathrm{cm}^{2}$ irradiance was illuminated for 1 minute $\left(1.08 \mathrm{~J} / \mathrm{cm}^{2}\right)$. The illumination ring diameter was limited to $6.5 \mathrm{~mm}$ and focused on the whole interface including the incision. A bandage contact lens was placed after CXL. Postoperatively, the patient was prescribed topical $1 \%$ prednisolone eye drop for one month in a tapering dose. Topical $0.5 \%$ levofloxacin eye drop was used four times daily for one week.

The bandage contact lens was removed one week after surgery. At 1-month examination, the UDVA in the right eye was 20/20. Mild cornea haze was noted at the previous area of epithelial ingrowth. At 4-month examination, the UDVA in the right eye was 20/20 with manifest refraction of $+0.50 /-0.25 \times 180$. No recurrent epithelial ingrowth but minimal corneal haze was evident on slit-lamp examination (Figure 2A). Previous focal abnormalities in keratometry and pachymetry had resolved on corneal topography (Figure 2B). Anterior segment optical coherence tomography revealed the presence of stromal demarcation line (Figure $2 \mathrm{C}$ ). Corneal wavefront measurement (Nidek OPD-Scan III; Nidek Technologies, Aichi, Japan) was performed for both eyes. The total corneal coma aberration at 6-mm zone was $0.453 \mu \mathrm{m}$ and $0.389 \mu \mathrm{m}$ for the right eye and left eye, respectively. The corresponding total corneal higher-order aberration was $0.883 \mu \mathrm{m}$ and $0.761 \mu \mathrm{m}$.

According to a safety report of over 1500 SMILE procedures, 10 eyes suffered from clinically insignificant epithelial ingrowth near the incision. ${ }^{2}$ Only half of these cases returned for examination after 1 year, where the epithelial ingrowth had resolved spontaneously. There was a reported case of recalcitrant epithelial ingrowth at the visual axis after SMILE. ${ }^{3}$ Repeated flap lifting and scraping followed by mitomycin C application or flap suturing failed to prevent recurrences of epithelial ingrowth. The 
patient was successfully managed after surgical debridement followed by application of hydrogel sealant to the flap edge.

We applied intrastromal CXL after scrapping and irrigation of the interface pocket aiming to prevent recurrence. Adhesion between corneal flap and the stroma was found to increase after CXL in laboratory investigations involving creation of corneal flap. ${ }^{4}$ Clinically, combined CXL during laser in-situ keratomileusis (LASIK) led to increase difficultly of performing a re-lift because of strong flap adhesion. ${ }^{5}$ The authors also reported the presence of transient corneal haze after CXL in LASIK using a total dose of $2.7 \mathrm{~J} / \mathrm{cm}^{2}$. We also noticed the development of corneal haze after CXL in the early postoperative period. It was found to subside gradually and became visually insignificant over time.

The success of treating epithelial ingrowth in refractive surgery depends on complete removal of epithelial cells and prevention of recurrence. Here, we describe a case in which clinically significant epithelial ingrowth was removed by debridement without flap lifting and followed by the use of CXL to seal the stromal interface pocket. This is the first reported use of CXL in management of epithelial ingrowth in refractive surgery. 


\section{REFERENCES}

1. Moshirfar M, McCaughey MV, Reinstein DZ, Shah R, Santiago-Caban L, Fenzl CR. Small-incision lenticule extraction. J Cataract Refract Surg 2015; 41: 652-665.

2. Ivarsen A, Asp S, Hjortdal J. Safety and complications of more than 1500 small-incision lenticule extraction procedures. Ophthalmology 2014; 121: 822-828. 3. Thulasi P, Kim SW, Shetty R, Randleman JB. Recalcitrant Epithelial Ingrowth After SMILE Treated With a Hydrogel Ocular Sealant. J Refract Surg 2015; 31: 847850.

4. Tao C, Sun Y, Zhou C, Han Z, Ren Q. Effects of collagen cross-linking on the interlamellar cohesive strength of porcine cornea. Cornea 2013; 32: 169-173.

5. Seiler TG, Fischinger I, Koller T, Derhartunian V, Seiler T. Superficial corneal crosslinking during laser in situ keratomileusis. J Cataract Refract Surg 2015; 41: 2165-2170. 


\section{FIGURE LEGEND}

Figure 1: Clinical presentation before epithelial ingrowth removal and collagen crosslinking. Slit-lamp photograph showing superotemporal epithelial ingrowth within the cap-stromal bed interface from the SMILE incision (A), corneal topography showing focal steeping in keratometry and thickening in pachymetry at the area of ingrowth (B), anterior segment optical coherence tomography showing hyperreflective epithelial nests at the interface (C).

Figure 2: Clinical presentation after epithelial ingrowth removal and collagen crosslinking. Slit-lamp photograph showing absence epithelial ingrowth but minimal haze within the cap-stromal bed interface $(A)$, corneal topography showing absence of focal abnormalities in keratometry and pachymetry (B), anterior segment optical coherence tomography showing the stromal demarcation line after crosslinking (C). 


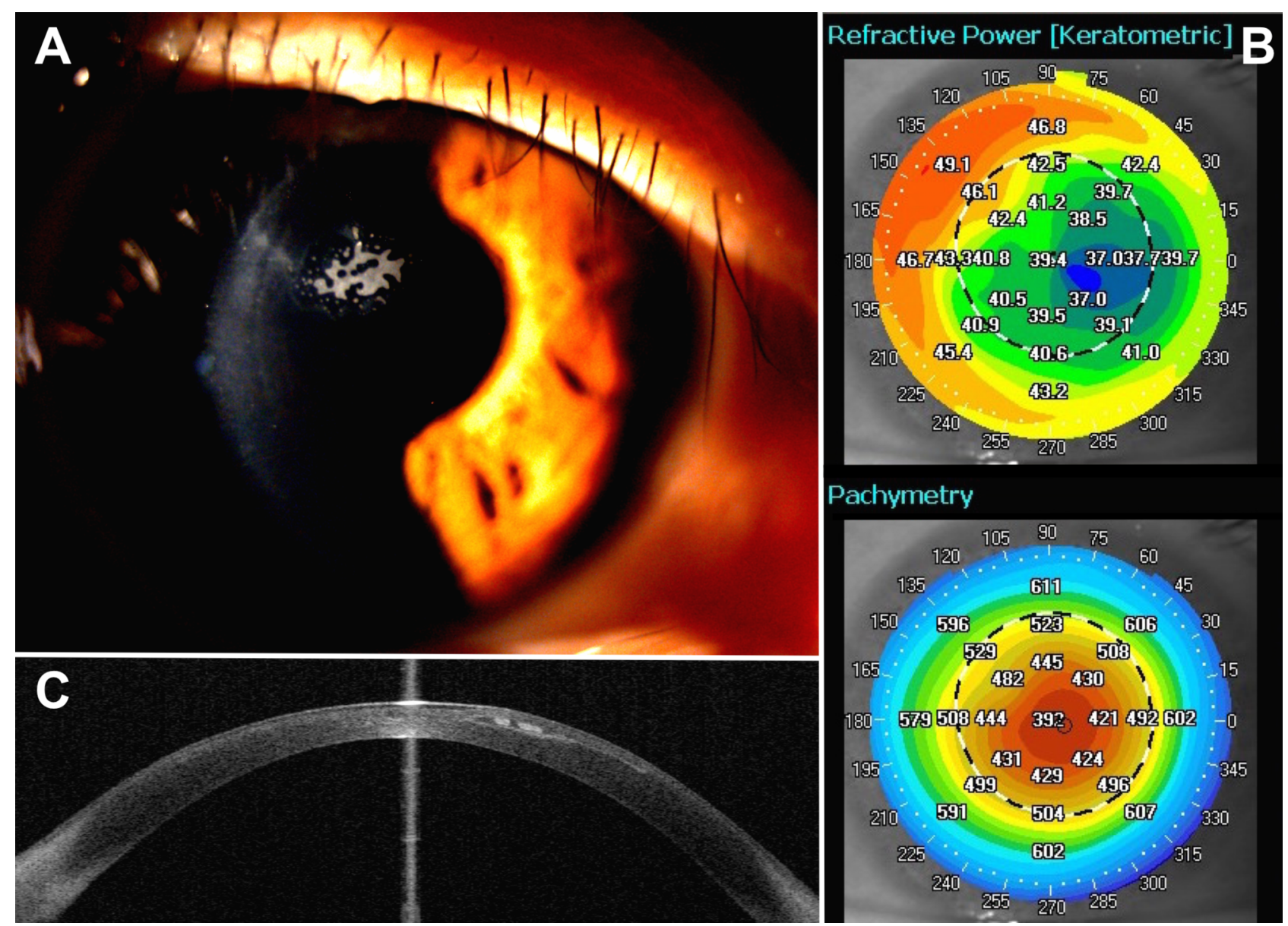

Figure 1.tiff

This article is protected by copyright. All rights reserved. 


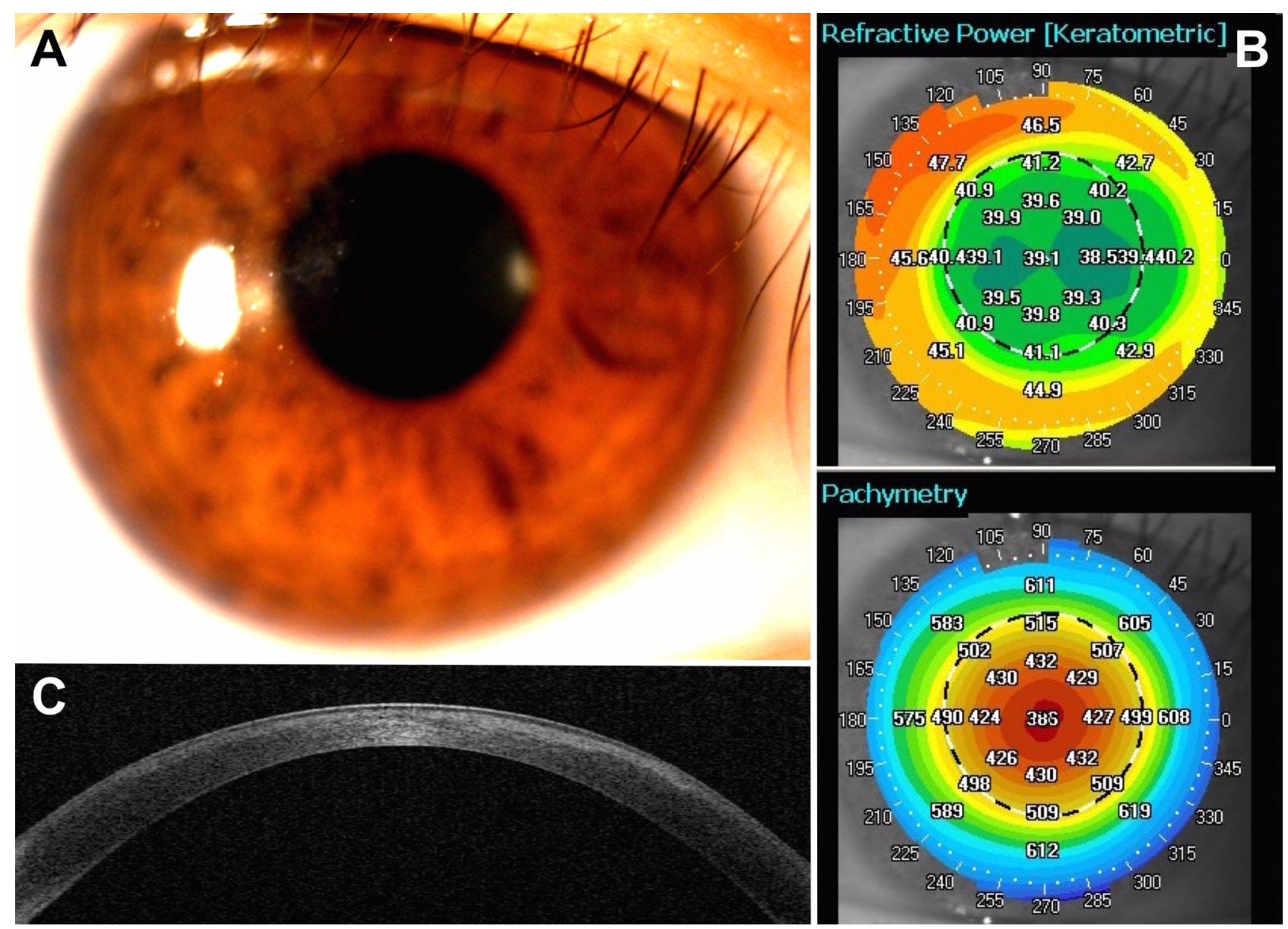

Figure 2.tiff

This article is protected by copyright. All rights reserved. 


\section{University Library}

\section{- M M N E R VA A gateway to Melbourne's research publications}

Minerva Access is the Institutional Repository of The University of Melbourne

Author/s:

Chan, TCY;Cheng, GPM;Jhanji, V;Wang, Y

Title:

Adjuvant collagen crosslinking for treatment of epithelial ingrowth after small-incision lenticule extraction

Date:

2018-07-01

Citation:

Chan, T. C. Y., Cheng, G. P. M., Jhanji, V. \& Wang, Y. (2018). Adjuvant collagen crosslinking for treatment of epithelial ingrowth after small-incision lenticule extraction. CLINICAL AND EXPERIMENTAL OPHTHALMOLOGY, 46 (5), pp.554-556. https://doi.org/10.1111/ceo.13094.

Persistent Link:

http://hdl.handle.net/11343/293938 